\title{
Libraries as Life-Systems: Information, Entropy, and Coevolution on Campus
}

\author{
Timothy C. Weiskel
}

\begin{abstract}
Just as the study of natural life-forms has benefited from the insights of ecologists, so too our understanding of the university library and its future evolution can be enriched by studying the changing ecology of information flow on campus. The introduction of new technologies for generating, storing, and transmitting information will radically alter the character, magnitude, and direction of information flow on campus in the years to come, just as these things are likely to shift in our society at large. In response to these evolving technologies, major institutional changes can be anticipated. As the group primarily concerned with designing the environments for storing and recalling these new types of information, university librarians need to be attentive to the delicate intellectual life-forms that may well be extinguished by massive or pervasive shifts in the library environment. Their choices need to be wise, kind, and careful.
\end{abstract}

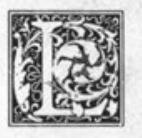

ibraries, as we have come to know them, are an endangered species, and they may well become extinct. This is so not because they are operated by dinosaurs, mastodons, and saber-toothed tigers, nor because they serve wooly mammoths, giant sloths, and dodo birds, but rather because, like the vulnerable carrier pigeon, they are a life-form that coevolved with mankind to meet specific needs during a phase of its social development. As human information needs change radically in an altered information environment, so too will the life-forms that will coevolve to meet these needs.

\section{PROCESS AND FORM IN LIFE-SYSTEMS}

Process, perhaps even more than form, constitutes the defining characteristic of life-systems. We know something to be what it is because it does what it does. Yet we need to guard against some conceptual mistakes here. The commonsense contrasts between structure and function, morphology and physiology, form and process are not ultimately defensible when life-systems are viewed over time. At any one moment it may be true that form, morphology, and structure all contain process, physiology, and function, but in the long run the former attributes express the latter. Form is the residue of process.

A careful study of a termite hill reveals the nature of relations between its former living inhabitants. The termite hill is clearly an object, but it is best understood as what archaeologists call a "processual object" - that is, an artifact whose structure reveals something about the process of its creation as well as its reason for existence. The intention behind examining things in this manner is to "read" processual objects for information about the

Timothy C. Weiskel is an associate professor in the Department of Anthropology, Yale University, New Haven, Connecticut 06520. This article was presented in its original form at a seminar sponsored by the Research Libraries Group in November 1985 at Conoco's Purple Sage Ranch in Bandera, Texas, through the hospitality of Conoco, Inc. 
processes they were designed to facilitate.

Only in this manner can we come to understand why some life-forms have become extinct. It seems that extinction tends to occur when the processes that characterize life-systems change more rapidly than the structures that contain them. At that point either the structures themselves change or, more frequently, they fail to reproduce effectively, and other structures take their place as the vehicles of life process. The transformation or transition from one structure to another is itself a kind of "metaprocess" of evolution. As processes of information-flow change on campus, university structures also change. In this fashion we are eyewitnesses to the evolution of life-forms.

\section{THE LIBRARY AS A PROCESSUAL OBJECT}

All of this is familiar enough to any student of natural history, but when we begin to "read the library" as a processual object in this manner, some interesting phenomena come into focus for us as scholars and librarians. As a first step we need to look beyond the objects so familiar to us in this environment and examine instead the processes these objects are supposed to embody or facilitate. Let us begin with some commonsense definitions of the library and see where this kind of approach will lead.

If you ask most freshmen "what is the library?" the response is likely to be something on the order of "the place where they keep the books, dummy." This is a true but trivial definition, for clearly it is much more. By sophomore year, most students have discovered that there are a lot of other kinds of documents in the library. Maps, sound recordings, microfilms, newspapers, coin collections, postcards, private papers, etc. are all now considered to be part of the research library's appropriate inventory. To be accurate, then, the definition of a library has to expand considerably beyond a freshman's understanding. One provisional definition could be

\section{A library is any institution that contains consultable documents.}

This definition is at least a little more po- lite than the utterance of our freshman, but it still betrays our object-oriented parochialism. We have not yet come to focus on process. Instead we have merely expanded the notion of "the book" into that of "the document." Let us turn for a moment, then, to look at the series of processes embedded in the notion of consulting a document.

As we focus upon process it becomes clear that the scholar's concern is not primarily with books or documents as artifacts, even though personally he or she may be a bibliophile or a closet archivist. The absurdity of the following imaginary conversation makes this clear:

Bookseller: Do you want to buy a book? Scholar: No thanks. I already have a book.

A scholar might say this about a car or a loaf of bread, but not about a book or a document, because it is not these things as artifacts that interest him in the first place. Instead, in his research capacity the scholar considers documents as precious vehicles of information that provide windows upon the thought process and life conditions of other human beings. Any document or book is a communication device or channel, characterized by its capacity to store and "carry" encoded information. Conversely, any vehicle or carrier of encoded information constitutes a kind of document.

This requires some elaboration, and concepts developed in information theory and thermodynamics may be helpful in providing some simple definitions that reveal the fundamentals of the processes we are trying to examine. According to information theorists, information is any nonrandom arrangement of matter or energy. By contrast, the random arrangement of matter or energy is maximum entropy. Information is its opposite. Information is thus, "negative entropy" or "negentropy." It is not the same as matter or energy, but differential states of matter or energy can convey it. It is not itself a "thing" but rather a relation between "things" or states of energy over time.

In this sense information is preeminently involved with process and movement, for it can only be said to exist as a manifestation of differential states of mat- 
ter or energy, that is to say, a variation of these things from their most probable arrangement-absolute randomness. Information may seem to be stable and nonvariant, but as the second law of thermodynamics suggests, such stability is illusory. Any discernable arrangement of matter-energy that is not random is but a stage in the process of becoming so. All structure is becoming unstructured.

This fact, though universal in nature, smacks the academic community in the face in a particularly rude way. Information is "negative entropy," yet the world at large is entropic. To the extent that scholars and librarians try to build and maintain information systems, they are struggling against the laws of the universe. Theirs is the task of Sisyphus. Libraries, then, when viewed as processual objects reveal themselves to be either stupendous miracles or grand tragedies and perhaps both.

The reason for this has to do with processes inherent in information itself. Information is borne on "markers" recognizable bundles or units of matterenergy-whose arrangement conveys meaning within specific symbol systems. Markers are in turn observed through or carried on "channels." Thus, viewing the patterned arrangement of ink molecules on a page or hearing the fluctuating pulsation of sound waves over headphones both represent acts of perceiving markers over specific channels. Once again, the emphasis here is upon process and event, not upon stasis or object.

\section{INFORMATION AND CHANNEL SWITCHING}

We have come to see, then, that what we usually refer to as information is not information at all. Strictly speaking, a book or a tape is not itself information, for information is not a "thing." Instead these things are channels over which markers that convey information are transmitted. Some might wish to argue that channels not only carry information markers but actually allow us to "store" these markers in permanent form. But such a notion ignores thermodynamics, and as any manuscript conservator can tell you, it is nonsense. Since the structured arrangement of matter-energy is itself not permanent in the universe, no library can aspire to be so. Markers may be stored on particular channels for very long periods of time but not forever. We must try to preserve the state of the channels as long as technically possible, but the best we can hope for by way of permanence is to provide translation or transformation devices to assure the faithful transmission of the information content from one channel to another.

This focus on process leads us to a more accurate, though rather more longwinded, definition of what a library is than that offered by our hapless freshman.

A library consists of a collection of information markers and the requisite means for storing them, consulting them, decoding them, and faithfully transmitting them from channel to channel in order to examine the nonrandom arrangement of matterenergy that their patterns represent.

It may not be more polite in this form, but the purpose of this redefinition is to enable us to think more clearly about the relationship between process and form in the library. From this perspective we can see that the library's essential functions are not wedded irrevocably to the "channel" of the book, nor for that matter, to any other particular channel. There is no functional reason-though there may be important historical ones-why the book should be the center of a library's attention. In fact, there may be very good reasons to abandon this channel or indeed any other channel if it no longer serves as the most efficient, most reliable, or most convenient channel available for the storage or transmission of information markers.

Ultimately the reasons for switching channels have to do with two phenomena: (1) the problem of "noise" and (2) intrinsic channel capacity. Noise is the nonpatterned matter or energy that is carried on a channel along with information markers at any one point. It can vary over time, and one of the reasons we say that a channel is deteriorating is that its noise level is getting too high. Too high for what? Too high for us to be able to distinguish the noise from the signal itself. When the level of noise increases beyond a certain point it becomes progressively 
more difficult and eventually impossible to perceive the information markers on the channel. Thus, when the ink fades and the paper browns, or the scratches on the record produce too much static, or the stray white marks on a microfilm become too numerous, these channels can be said to convey too much noise, and our ability to "read" the information markers accurately from them can be impaired.

At this point any good librarian begins to consider transmitting the information markers from the channel in question to one with less noise so that the integrity of the information can be maintained for those who wish to consult it. The functions involved here include the classic ones of conservation and preservation but also those of photoduplication, xeroxing, rerecording, microfilming, etc. These latter activities require the explicit transmission of information from one channel, or medium, to another, and many libraries now consider the provision of these functions to be an integral part of their everyday tasks.

There is another reason beyond that of "noise" that draws librarians to become involved in the channel switching of information markers. This concerns the limits of the channels themselves. Each channel has its own upper limit as a carrier of information. When these limits are exceeded, the transmission of information through it begins to decline and can ultimately shut down altogether. In this sense, librarians often become involved in the transmission of information from one channel to another, not because the informational integrity on the old channel is threatened with noise, but simply because another medium has a higher channel capacity and is therefore more convenient, economical, or efficient for the storage or transmission of information markers.

Differences in channel capacity are truly staggering, and technical advances in the development of new kinds of channels have been enormous in recent decades. Consider, for example, the following description:

Cuneiform tablets carried approximately of the order of $10^{-2}$ bits of information per gram; paper with typewritten messages carries approxi- mately of the order of $10^{3}$ bits of information per gram; electronic magnetic tape storage carries approximately of the order of $10^{6}$ bits of information per gram; and it has been demonstrated that one can write with microbeams, through a demagnifying electron microscope on ultrafine grain films of silver halide in letters so small that they could store the content of more than a million books on a few cubic centimeters of tape, about $10^{12}$ bits per gram. ${ }^{3}$

Clearly there are major differences of convenience, efficiency and economy involved in the choice of channel. Choices are made all the time between alternative channels in a library, but not all channels are equally favored by librarians. There is a general trend toward favoring those channels with the greatest channel capacity, durability, and freedom from noise, yet there are very real operative limits imposed by the library's traditional selfdefinition. It is precisely this traditional self-definition that is now coming under scrutiny because of the expanded technical capacities of newly available channels.

Consider a trivial example. It is technically possible to transmit the information in the Manhattan telephone directory onto cuneiform tablets, but the advantage of doing so is not obvious. Since no user would want it in this form, no library considers providing it on this channel. User convenience is determinative. Or is it? Not quite. The advantages of making that same information available on electronic tape or machine-readable disk are considerable for a whole variety of people. Certainly access to a machine-readable form would be convenient for the user. In addition, since it is probably initially compiled by the telephone company in electronic form anyway, and since the printing costs of going into hard copy with this information are considerable, the telephone companies themselves may soon see the logic of "publishing" their information markers on electronic channels rather than through the channel of the inked page. But what about the library? What is its attitude to channel switching of this nature? Is it forever limited to dealing preeminently with one channel alone, that of "the book"?

Few libraries would consider their refer- 
ence rooms to be complete without a copy of the Manhattan telephone directory. Yet at this point very few indeed could hope to provide access to it if the telephone company provided it on a tape cartridge or a hard disk. Moreover, virtually none would know even what to say to a request from a student to have the phonebook "scanned" with a Kurzweil 4000 optical character reader (OCR) so it could be provided to him or her on a tape to take home and examine with a microcomputer text analysis program. All of this is, of course, technically possible. Even freshmen are aware of this. Freshmen are also aware, however, that the library is not ever likely to provide this kind of service for the transmission of information onto an electronic channel.

It is not that librarians are against the technology of miniaturization. On the contrary, for very practical reasons they have championed the transmission of information from more extensive to more compact channels to increase the efficiency of its manipulation. I suspect, for example, that much of the microfilming that goes on in libraries today is taking place primarily in order to save space and provide convenient access. Here the primary concern may not be the maintenance of the full and faithful integrity of the information itself. Some information is inevitably lost as noise in any transmission, but the calculation is that whatever information is lost is not significant. Whatever is lost is more than compensated for, so the logic goes, by the convenience of access and durability of the new channel to which the information is transmitted.

Even durability may not really be the primary concern. After all, we are not that confident that film can be maintained over long periods of time, say hundreds of years, all that much better than paper and ink, yet virtually all libraries have committed themselves to transforming large portions of their collections, and acquiring whole new ones in this medium. Software will pose even more dilemmas in this regard, for we have no long-standing experience in the reliability of electronically stored information markers.

The activities involved in the channel switching functions of a library require an enormous commitment to machinery, personnel, technical processing, and operational facilities that have little to do with books. Yet few libraries any longer feel they can afford to forgo these activities totally, for all have come to realize that transmission of information markers from one channel to another is a vital part of their mission.

The question is no longer whether these functions should be performed, but rather: Under what conditions? For whom? How frequently? From what media to what media? What limits should be imposed on this infinitely expandable activity? Who should impose them? When provided, what costs should be borne by the library itself? What costs should be passed on to the library's clientele? Is "price" a fair delimiter of access? In a market-integrated democracy, what is "fair"? etc. All of these issues are operational manifestations of a larger underlying question of values: What relative importance should channel switching assume in the library's overall mission?

My own suspicion is that if libraries are to survive as life-forms in evolutionary terms they will have to devote a greater proportion of their functional effort to these channel-switching activities than they have in the past. This shift in function will undoubtedly have structural implications. Libraries that take on channel switching as a major portion of their activity are no longer going to be spacially organized around a card catalog, a circulation desk, "stacks," and a reference room. The beast will have a different shape. But more of this later, when we consider problems of coevolution.

\section{THE LIBRARY LIFE-FORM IN ITS UNIVERSITY ENVIRONMENT}

So far we have focused upon the processes that go on within the library as someone tries to use it. There is, however, another level of consideration. It is possible to move beyond the transactions that occur within a library, and focus instead upon the way in which the library itself takes on the characteristics of a whole living organism within a wider system. As 
we shall see, these two levels of analysis are related, but for the moment let us turn to the attributes of a library as an organism situated in its wider environment.

Like all other life-systems, libraries are defined by characteristic exchanges of matter-energy and information with their environment. In this, libraries experience flux in the flow of matter-energy and information with their environment, and their vital processes largely involve the regulation of that flux. The quantities and rates of flow of these things are to a large extent autoregulated, since life-forms can only persist within certain ranges of these flows. They must process matter, energy, and information at certain rates in order to maintain their structure in relation to their environment. In short, libraries are not static, they are homeostatic.

All of this sounds manageable enough. As long as the flows of life rendering constituents are maintained within tolerable limits, the life of the organism should go on without difficulty. But what are the prospects that these life sustaining flows will be maintained within survivable limits?

Here's the rub. There are numerous signs, increasing every year, that we are in for some major perturbations of these flows. There is a lot of breathless drivel published in each new issue of popular magazines concerning the "information revolution." Most of it is "tech hype" and not worth serious commentary. Nevertheless, it is worth examining the ways in which changes in kinds or flows of information are likely to alter the operative environment of the delicate life-form of the library.

The immediate reasons for impending change in the flow of matter-energy and information to and through libraries are fourfold. First, microelectronic circuitry has enabled manufacturers to miniaturize computing power into highly mobile systems, allowing students to carry sophisticated computers directly to the points of customary information access. It is now quite feasible to enter notes from the laboratory, the lecture hall, or the library directly into electronically encodable storage memory.
Secondly, software programs and communications technology have advanced to the point that individual micros, picos, or hand-held computers can now be easily integrated with larger systems. This allows faculty and students to employ very powerful techniques of manipulation and analysis on vast amounts of information available through convenient access to external integrated computer networks. In the coming years the library will be just one of several available nodes in this information web. It will tend to be used only to the extent that it offers either unique kinds of information or commonly available forms of information that are less expensive and/or more convenient than those offered elsewhere in the new information environment.

A third key element in the shifting ecology of the library as a life-form is a new breed of organisms in the university, organisms that are at the very least a new form of information-parasite and potentially an information predator upon the library lifeform itself. This new breed is the computer-literate college student. Technically speaking, this is not a new species of organism, but rather a particular population characterized by a radically new information-processing metabolism and a voracious, omniverous, and largely indiscriminate appetite for information. It is a fact that for the first time a computerliterate population is beginning to fill the ranks of the college student community.

The transition is taking place in stages. For the last several years it has been true that in many institutions the freshman class often knew more about computers than the senior class, reversing the classic profile of technical competence. In the next few years, however, this will change in those institutions where it has not already done so. One of the key authorities for news about the growing online community has quantified the change in these terms: "An estimated 80 million users of such services will be online by 1987 (compared to 400,000 in 1983). ${ }^{\prime \prime 4}$ Even allowing for a substantial margin of overestimation here, it is clear that shifts in order of magnitude may well be involved in periods as short as three to five years. 
The result is that from their point of entry, and cumulatively as they progress through college, student populations will expect to use computers as study aids and production tools for whatever they wish to undertake. Given the radically altered information metabolism of this population, their normal feeding habits are likely to affect other life-forms around them, particularly those to whom they have been taught to turn in the past for nourishment.

Professors and libraries have traditionally been the life-forms upon which the student population has attached itself as information parasites. Of course in overall systemic terms this population lives in a symbiotic relationship with the university at large because it offers matter-energy inputs in exchange for the matter-energy and information it extracts. In terms of information flow alone, however, it is still substantially accurate to characterize this population as parasitic on library and faculty life-forms.

Information parasites attach themselves to hosts and benefit from an asymmetrical and largely unidirectional flow of information, which saps the vital processes of the hosts without actually killing them. Libraries and faculty alike are often left in a severely weakened state by information parasites. If they are to reestablish their vitality, it will be largely through efforts they make to obtain nourishment from the administration-that controlling organism to which the incoming student population of information parasites has yielded its resources to establish its symbiosis with the university in the first place.

The fourth changing aspect of the environment that is likely to alter the flow of life-bearing matter-energy to and through the traditional library life-form is the emergence of new organisms within the living tissues of the university itself. Specifically, computing facilities seem to be burgeoning everywhere on campus and growing at what some might describe as a cancerous rate.

Whether they are located in centralized computer centers, departments or residential college dormitories, computerized information nodes are comparatively young but fast-maturing organisms in their own right. They too attract the growing populations of incoming information parasites, and in many ways they are better adapted to serve as hosts for these populations. To the extent that they begin to carry greater and greater numbers of these information parasites, these new organisms also require flows of matter-energy from the central administration in order to sustain their life processes.

With respect to the central administration, and in some cases in relation to the population of information parasites as well, these new organisms within the university occupy a niche that overlaps that of the library life-form. In terms of their respective dietary needs, this is clear. Both the computing organisms and the library life-forms require roughly the same kinds-though perhaps different magnitudes-of green matter to keep themselves functioning.

As far as the information parasites are concerned, each of these life-forms represents a slightly different niche, for although it is true that each of these organisms can provide nourishment of roughly similar informational content, the information markers are provided on widely different media. Past populations have been content to graze upon a highfiber diet, and for this the library life-forms have served them very well. As we have indicated, however, there are signs that these feeding habits are changing among the new populations who are more accustomed to celluloid than cellulose.

Consider, for example, the gluttony of our telephone-book enthusiast. There are some members of the new population of information parasites who actually do expect to find massive amounts of information served to them on machine-readable channels. Perhaps not the Manhattan phone book itself, but other similar delicacies, such as United States census data or World Bank national accounts data or New York City Bank economic data, are known to be packaged in this form. A Wellesley, Massachusetts, firm, appropriately called SilverPlatter Information Inc., is beginning to serve up "megamorsels" of this scope, including the Educational 
Resources Information Center (ERIC) database, to specialized researchers who can afford them.

In fact, the whole issue of machinereadable data is already well beyond the domain of specialized researchers. Compact Disc-Read Only Memory (CD-ROM) is revolutionizing the presentation of standard reference tools in the library, affecting the basic and most widely used of a library's services to students and faculty alike. It is only recently that many universities have developed online searching capabilities that require hardware investment, accounting, training of personnel, etc. Now whole portions of this domain of information are already migrating off the mainframes of large vendors such as Lockheed Dialog. Instead, the information is being provided by the primary data compilers to customers directly on CD-ROM discs. These come in either 12 -inch laser disks or 4.75-inch (12-centimeter) CDROMs.

The evolution of this media has been staggering, in just a few short years. ${ }^{5}$ It is still common, for example, to see a hardcopy version of Books in Print (BIP) in any reference section of a library. At the same time, however, it is now frequently consulted, in institutions with the appropriate equipment, in its online form through electronic links to vendors like Lockheed Dialog or Bibliographic Retrieval Service (BRS). Despite the seeming breakthrough in convenience and speed, this is likely to change yet again in the coming months. In all likelihood BIP will soon be consulted more conveniently through a computer terminal connected to a CD-ROM player, with a current version of BIP provided directly to the library from the publisher, $R$. $\mathrm{R}$. Bowker. The same will be true, no doubt, for Ulrich's International Periodicals Directory and for the Public Affairs Information Service (PAIS). H. W. Wilson Company also apparently intends to sell CD-ROM versions of its Cumulative Book Index and Readers' Guide to Periodical Literature. Many of the basic bibliographic reference services are contemplating plans to sell CD-ROMs directly to users with subscriptions to quarterly updates: ${ }^{6}$
Moreover, publishers of other large reference materials are likely to follow the exemplary lead of Grolier Electronic Publishing, which in mid-1986 issued the Electronic Encyclopedia, a CD-ROM version of its twenty-volume Academic Encyclopedia. The hard-copy version of the Encyclopedia contains ten thousand pages of printed text, representing sixty megabytes of information. All of this can fit easily upon a single 4.75 -inch CD-ROM disk, and students can use the powerful electronic searching capabilities of the accompanying software to scan, select, print out, or save needed information-in seconds on floppy disks-for further manipulation with word processors or other software.?

Indeed, in the coming years very important portions of published information, once available freely to libraries in hard copy, may simply no longer be available in any form except machine-readable ones. Government agencies, in would-be costcutting gestures, are comtemplating dropping the paper publication of many document lines previously provided to depository libraries and substituting machine-readable tapes. Since researchers need these types of information in this form in order to scan them for meaningful patterns, it is logical to expect the information organisms on campus to provide them in such a usable form. Can libraries cope with this prospect? Do they even want to? Should they want to?

In the current state of affairs, freshmen already suspect, and sophomores most certainly know, that such forms of information-though they may be vital for their particular inquiries-are probably not going to be found in the library. So sure are they of this that they simply never ask for them. They are not likely to be there, so why embarrass themselves and others by asking? Very quickly they learn what information to expect and what not to expect from the library.

If they really need this kind of information, or similar masses of data in electronic form for rapid analysis, these students have learned to go elsewhere, for the library can no longer meet their information 
needs. The computer center may be of more assistance, but even this is not assured. The corporate library of an average insurance company may have become a better-equipped environment for many sociologists to pursue their work than the average university library. It is a sad fact of the "information revolution" that, over the last few years, universities as a whole-even with all their new facilitieshave diminished in relative importance as channels through which people seek information for research purposes in our society.

So what is so tragic about this? On the face of it, it might seem advantageous for library life-forms to rid themselves of information parasites and regain some of their vitality in this fashion. Such a strategy seems well conceived at the organismic level, but unfortunately it bespeaks a naïveté about the functioning of the university ecosystem as a whole. It must always be borne in mind that, although in their relation to the library, students and faculty are information parasites, in relation to the university as a whole they are life-sustaining symbionts. The administration receives vital flows of matterenergy from them, and it has a very real interest in catering to their needs.

As part of this process, the administration monitors flows between the information parasites and all life-forms on campus. Shifts in the relative flow of matter-energy to library life-forms may well result from administration perception that the needs of information parasites are better served by other life-forms on campus. If there is a greater demand for gaining access to information in computerized form than in conventional forms, the administration may well decide to shift resources. In my own university those who regularly use social science information are beginning to wonder if the library can hope to provide what they really need in terms of database access. There is serious talk of setting up a computerized, alternative, social science "decision support system." Clearly then, it is necessary to develop an understanding of how the ecosystem as a whole works to be able to judge the evolutionary prospects of any one life-form within it.

\section{THE COEVOLUTION OF LIFE-FORMS IN UNIVERSITY ECOSYSTEMS}

Over the last several decades students of living systems have made us aware that all life-forms have an appropriate ecology. The ecology of a life-form consists not simply of its surrounding inert environment but also its integral relations with other life-forms, some of which may have radically different ways of processing matterenergy and information.

In many cases, individual life-systems have only come to exhibit their present characteristics because of their coevolution with other life-systems. Because of symbiotic dyads neither organism would exist in quite the same way without the other, since each organism depends upon the other to meet its own needs. The extinction of one implies a radical change in, or perhaps even the corresponding extinction of, the other. The emergence or introduction of radically new species tends to alter the operating parameters of all the others. Similarly, general systemic changes in the rates and amounts of matter-energy and information flow in the system can have similar disruptive effects.

All of these shifts in ecosystems provoke existing species to adopt a variety of survival strategies. For example, to the extent that two or more life-forms come to occupy the same or overlapping niches in the system, they may become locked in battles of competitive exclusion for the same resource base. It would be a mistake, however, to think of these evolutionary struggles in gladiatorial terms. There may be dramatic encounters along the way, but these will only serve to punctuate a much more subtle and gradual process. In evolution we are dealing with survival of the "fittest," not survival of the "fattest."

Indeed, in an age of heightened matterenergy and information flow, the "fattest" may be at a distinct disadvantage, for they lack mobility and have to devote a large portion of their matter-energy intake simply to functions of system maintenance. My own university has recently de- 
voted hundreds of thousands of dollars to repointing the masonry in one of its library buildings. Meanwhile the computer center's infrastructural expenses involve changing light bulbs, and even this is not done very often. If there is survival advantage in being lean, clean, and mean, there is no question as to which organism will emerge victorious.

The issue of fitness, then, is not one of size or momentary strength; it is one of relative reproductive success over time. Library life-forms need substantial investments of budgetary green matter to reproduce themselves socially and maintain themselves physically over time, and this is not forthcoming without a willful commitment on the part of the university administration. Moreover, it is only likely to be forthcoming so long as the library is seen to provide essential and nonredundant services to the university's major symbionts. Rational administrations do not look kindly for long on reduplicated effort or wastage, and for this reason they are not likely to tolerate battles of competitive exclusion for common niches within systems they administer. This in itself is a very powerful reason for suggesting that the major form of evolutionary change will not involve these kinds of battles for very long. There will be strong selective pressure exerted in favor of other behavioral strategies for survival.

One possible alternative strategy for life-form survival will be conscious or unconscious specialization, leading eventually perhaps to further speciation. Organisms will either attempt to differentiate their consumption needs or change their characteristics as hosts to avoid competition with other life-forms within the system. Thus some information-processing life-forms can limit themselves to dealing only with one kind of channel-books, maps, tapes, etc. Others may choose to diversify their feeding strategies, in search of green matter outside the university itself, simply in order to be able to maintain or expand the number of channels through which they can offer information to clients.

Perhaps more probable, however, is yet a third strategy often witnessed in natural systems, and that is the one of behavioral mimicry or morphological imitation. As one scientist explains the phenomenon:

The Bee Orchid (Ophrys apifera) contrives to resemble a female bee: male bees are attracted to the plant, transfer pollen from one plant to another, and so accomplish fertilization. In a similar spirit, the Tartan Tongue Orchid of Australia has flowers which resemble the females of a certain Ichneumon wasp. Another Australian orchid imitates an ant. Some moths imitate the hornet; a hoverfly mimics the honey-bee; and a beetle resembles a wasp. There is even a case of a spider, holding its front legs aloft to look like antennae, struggling to mimic an ant. ${ }^{8}$

This may well be the best strategy for library survival both with reference to meeting the demands of the students and faculty and in terms of continuing to justify the library to the administration. In this vein, libraries will take on many of the capabilities of computer centers to handle electronic media and make documentation available in machine-readable form.

For their part, computer centers, for the sake of their own survival, will begin to adopt traits traditionally characteristic of libraries. Not only will they begin to cata$\log$, conserve, and archive material in much the same way as librarians have learned to handle books in the past, but, in addition, the nature of their user-service facilities is increasingly likely to match the convenient, efficient, and considerate reference service we have so long enjoyed in university libraries.

Coevolution will inevitably proceedeven if in the direction of heightened estrangement. Conceivably, for example, new breeds could emerge with accentuated defense mechanisms or patterns of behavior designed to foster avoidance. This would be unfortunate for the free flow of information within the system as a whole, and may seriously undernourish the resident symbiont populations. It is perhaps more likely, however, that convergence rather than heightened speciation will be the emerging coevolutionary pattern. If agents in charge of the organisms within the university begin planning now, they most certainly can influence the 
probable patterns that coevolution will take in the system as a whole.

\section{REMAINING PRACTICAL QUESTIONS}

All of this is a bit abstract and may have no more than metaphorical value in helping us to think about the coming problems. But in practical terms, just what are these coming problems? Predictions are about as reliable as palm reading or stargazing at this point. Moreover, in general terms things will probably not be transformed as quickly nor in the same directions as the agents of "tech hype" would have us believe. People are too complex and their purposes too diverse to make simple predictions meaningful. Nevertheless, we can pose some questions. Not all of the following general subject areas relate to the library itself in every one of their aspects, but they do describe some of the dilemmas that the new information technology will pose for the university environment in which libraries will evolve.

\section{Library Access with New Computing Power}

It is probable that students with a "hard card" installed in a lap-sized portable will be able to carry with them by the end of this school year as much as ten magabytes of information (roughly the equivalent of six thousand typewritten pages) in something a little larger than a notebook. Are libraries equipped to allow students to use these as note-taking devices throughout library premises? When libraries finally convert their card catalogs to machinereadable form, will they allow students and faculty to "plug in" to the catalog from their hand-held, lap-sized, or portable computers? Will libraries support a phone connection to the catalog? How many "ports" will be allowed for this? Will they be able to bear the hardware costs to meet this potential demand over the phone wires? Should students or faculty using this mode of access to the library's cataloging system be charged for it?

Assuming that technical and operational questions of online connection to the university's multiple libraries are solved, what kind of service should be provided once the online connection is achieved with ease? Will separate categories of users be created with differential access and privilege levels (determined perhaps by passwords)? Who will issue passwords: the library? the Bursar's office? Will there be any means of controlling unauthorized or fraudulent use of online access to the catalog? Who will assess cases of this sort? What will constitute "illegal" use of the system? Will users be able to undertake title, author, or subject searches and save the results on diskette? If so, who "owns" the information on the diskette? Will all university users have the freedom to copy, transform, and reformat the card catalog entries freely and for their own purposes, representing it as their own work?

\section{Problems of Keeping Transaction Records}

All libraries must keep track of which books circulate and to whom they afe checked out. The use of computers to do this allows librarians to monitor and analyze the usage patterns of their holdings in very important ways. Since decisions about future facilities, services and staffing require this kind of information, librarians would be remiss if they did not collect it and analyze it on a systematic basis. $\mathrm{Ob}-$ vious problems arise here, however, for this is potentially misusable information. In the past libraries may not have exercised a tight control over the pattern of their acquisitions because they did not fully control the information necessary to do so. With computers, however, it is possible to keep careful track on which books or which types of books are most heavily used. From strict cost-accounting perspectives it may make sense to focus acquisitions in this realm alone, since this reflects user preference as expressed by user demand. Is this appropriate? If not, what mechanisms are there to assure that these criteria are not important in collectionbuilding or -maintenance decisions?

Potentially more ominous is the undetectable ability of the library to track patterned user transactions. Few surveillance 
systems could be devised that would render as much information with such a low profile as one based upon a complete, real-time report of what an individual user has consulted in the card catalog or on the shelves or what he or she has checked out of a library. The application of computer technologies to library systems makes this kind of surveillance possible and perhaps even necessary. What mechanisms exist to assure users of the strict confidentiality they have come to enjoy in library transactions in the precomputer age?

\section{Training and Support}

To what degree should libraries assist students and faculty in conducting their library research in electronic form? Will they simply maintain up-to-date information on the development of computer technology on bibliographic manipulation so that faculty and students can go and read it for themselves? Should libraries instead take a more forward role in providing faculty and students with training in how to use the resident systems or how to interface the resident system with a whole variety of privately available pico- and microsystems? If only some micro-interfaces are supported by the library, which ones shall these be? On what basis should they be selected? To what extent should they be supported?

\section{Programming and Staffing}

Should libraries recommend or endorse bulk purchase and resell communications software that they know works best with their systems? How will they keep abreast of what is being produced in document handling and bibliographic software that would be of use in this regard? Are they prepared to hire staff to serve as full-time faculty/student advisors on documentary computer matters? Should libraries instead employ programmers to develop applications software that is custom-made for their installations? Or, should they employ programmers whose full-time job is to assure linking capability to whatever software is available commercially? Should libraries develop a staff position for a computer coordinator to oversee the library's computer systems development in such a way as to allow it to communicate with itself and with others?

What will the extensive use of computers in normal library functions do to the pattern of library hiring and the structure of library personnel compensation? Will specialized computer skills become the necessary minimum for library hiring? Can the libraries afford to pay the going rate, in a competitive market with the business community, for the personnel with this training? If it cannot, how much of its resources must it devote to training initially unskilled staff in this regard? Once the staff is trained, how can the libraries hope to hold on to them if their skills are marketable elsewhere?

If computer skills become the new minimum floor of expertise needed for work, what is the fate of existing staff? Will the unprepared be fired or phased out? Should they have to bear the costs of their retraining? Should that retraining be provided in the library itself, or will librarians be told to "go back to school?" If so, where will they go for useful instruction at an affordable price? Does the retooling of the labor force mean the de facto devaluation of existing jobs? Will the progressive application of computer technology in libraries force a further accentuation of an already hierarchical labor force structure, whereby a larger mass of library tasks will be reduced to simple interactive routines with CRTs, while a diminishing portion of jobs involve responsibility, decision power, or even regular human interaction? What will this do to library salary structure, morale, and operating expenses?

\section{Online Searching Services}

Most university libraries now have online searching facilities with BRS, Lockheed Dialog, and ORBIT. Should these services be maintained, extended, or dropped as individual researchers develop their own capacity to access these sources? Where does the obligation to provide them begin? Where should it end? If they are maintained and/or expanded, what should be the practical limits set on their use? Who should have direct access to online search machines and search 
time: librarians alone? trained faculty and librarians? trained faculty, librarians, and students? Who will do the training of library staff? Who pays for training sessions: faculty? students? Should online search training be part of regular library instruction given to all freshmen? Is "not everyone wants it" an acceptable answer, given that so few people know it is available or know what it can potentially do for them?

Should libraries support this kind of service at all? Or should they let it be taken over by the "information brokers" now surrounding university campuses-those petit bourgeois entrepreneurs who not only do research for a fee, but probably "ghostthink" as well as ghostwrite papers for students? Will students be rewarded for handing in work (say an annotated bibliography) that can now be done by a computer? Should librarians, out of convenience to themselves, encourage users to conduct their library work in this manner? Should the full costs of this kind of work be passed on to the user? If so, in what sense has the library fulfilled its mission in an academic setting? Hasn't it instead merely transformed itself into an extended network of workstations for commercial information profiteers?

Where are the ideals of free and unimpeded inquiry - often pronounced on university campuses-in all of this? Do we live in a free society or a free-market (i.e., expensive) society? Should the flow of information be buffered from the influence of the free market in a free society? If information is power, and information is expensive, then the wealthy are powerful. Does the university and its library, by the way it provides access to information, have any role in the broader society other than that of simply replicating market relations of power?

Can the university really hope to sustain the costs of these forms of information? Some databases with timely economic information can cost as much as $\$ 1,800$ per month. Libraries already find serials in hard copy an expensive proposition as a sustained expense-what about electronic newsletter services and the enormous subscription costs they imply?

\section{The Desktop-Publishing Glut and Selectivity}

Are libraries prepared to cope with the publishing explosion implied by the imminent, widespread availability of laser typesetting printers? Within a few years, if not already within a few months, it will be feasible for small groups, such as university departments, research teams, or student groups, to publish individual reports, books, booklets, tracts, newsletters, journals, occasional papers series, etc.

The library has traditionally depended upon an arbitrary "filter" for ephemera, and confined itself largely to the acquisition of published material, usually from the reputable publishers. Laser technology, though it has been available for a while, is only now coming into the price range of the individual consumer. Furthermore, walk-in "copy shops" are making lasertypeset, camera-ready copy available for as little as fifty cents per page, and similar typesetting is available, for two dollars per $\mathrm{K}$ of text, over conventional phone lines.

This is likely to mean that the volume and variety of published material is going to explode in the coming months and years. The Xerox machine put the power of duplication into the hands of the common person. The laser printer will put the power of publication into the hands of anyone who knows how to use a keyboard. Much of what will be produced will not be worth collecting for preservation purposes, but some of it will. Furthermore, it is important for future scholars, in at least some libraries, to collect even the most trivial current ephemera in certain fields. I suppose Cooperative African Microfilms Projects (CAMP) programs could be devised on a massive scale.

Who will collect this material? If all of it cannot be obtained for practical reasons, what criteria of selection will be applied in acquisitions departments of libraries when this material begins to gush through the door-at a very low cost or perhaps even free? Will scholars be involved in determining the selectivity process, or will this be left to the professional librarians with their own sense of collection priori- 
ties? We may be past the time when a policy of total acquisition is feasible, but what will replace it when the flow in published form increases by orders of magnitude over what it was a few years ago or what it is today? Can a university research library afford not to acquire this newly published material and still fulfill its mission? How can a library avoid giving all its resources over to acquisitions and cataloging?

A proportionately small, but nevertheless quite massive and important, subset of this new flow of hard copy involves computer literature itself. New journals are appearing daily on subjects in the field, ranging from, on the one hand, the technical capacities of machines and detailed descriptions of hardware and software-programming problems to, on the other, more general or disciplinespecific journals such as Social Science Microcomputer Review, Computers and the Social Sciences, or Computers and the Humanities. Some libraries have done valiantly in keeping up with these, but there is room for improvement. How should acquisitions be handled here? Who should decide which subscriptions are established: librarians? faculty? students?

What about computer manuals, programming aids, or the like? These are publications whose immediate value is very high but that are outdated quite quickly, perhaps even in a matter of months. Given their short shelf life, should they be acquired at all? If so, which ones? If not, what are the hidden costs to the library of not having them in the collection, as students and faculty increasingly come to regard their libraries as useless for major realms of their concern? Nothing will increase user indifference toward a facility faster than a persistent pattern of inability to acquire what users need for their work. If libraries come to regard user needs as ephemeral, current users can quite easily come to regard libraries as dispensible. In coevolutionary terms, this is quite clear. As organisms evolve out of mutually beneficial symbioses, each can afford to do increasingly without the other. By not taking their users' needs in this realm into account, libraries could destroy a symbiotic relationship, the ultimate results of which would be detrimental to themselves. Yet to sustain the symbiosis, as the information-feeding habits of the symbiont population become all the more voracious, is a very expensive proposition indeed-one that will require a massive ingestion of budgetary green by the libraries themselves.

\section{Acquisitions, Cataloging, and Circulation of Electronic Publications, Software, and Data}

What about information on electronically readable media? Will the library establish a policy for the systematic acquisition of texts available on electronic tape, diskette, or CD-ROM? Already several journals appear regularly on diskette, and book publishers make diskette editions of their books available as well. For the moment these books are predominantly computer-program books with extensive code written in the text. It is not feasible for readers to retype lengthy code without making errors, so in the interests of accuracy, they will often buy the published diskette version of the book. Will libraries acquire these books/diskettes? Will scholars be able to consult these sources in this form?

Numerous literary projects are converting text to tape and making the results available for extended consultation. As scanning equipment for the conversion of printed material to electronic form becomes more widely available, the retroconversion of already published texts onto tape, disks, or CD-ROMs promises to be massive. Rutgers has begun a collection of this material in a systematic fashion. Will other university libraries follow? Should they? Or should Rutgers become an effective "national center for machinereadable text?"' Will any provision for interlibrary loan of this kind of material be made? Or is it better simply to make copies available as a form of electronically published editions? Once a CD-ROM master copy is made of a "closed" collection or whole corpus of selected texts, multiple copies of it can be replicated very cheaply, yet as this form of CD-ROM publishing of whole library collections becomes more widespread, guidelines for the acquisition 
and circulation of this material will have to be established. For research purposes it may be more practical for university departments, research teams, museums, or laboratories to acquire CD-ROM subscriptions to specialized materials with appropriate periodic updates. Clearly, not all university libraries will be able to afford to acquire all that will be produced in this form; yet if they do not, informationhungry researchers will migrate elsewhere, leaving the university library to shift its role from that of a major research resource to a collection of the lowest common denominator of usable reference tools.

Oddly enough, while economics of scale have led many university library systems to move away from the logic of decentralized departmental libraries in the recent past, new availability of CD-ROM research collections with periodic updating and retrospective conversion may radically reverse this trend in the coming years, restoring or establishing the autonomy of microlibraries dotted all over the campus. What will become of the whole idea of the university library in this context? Can it even hope to maintain "bibliographic" control or a union catalog of the university's holdings? Without careful planning and coordination between these semiautonomous research nodes, there could be an inordinate amount of duplication in CD-ROM acquisition with considerable reduplication of effort and expenditure.

What about acquiring and circulating software? Much is now available in the public domain as "free ware," "share ware," or "cheap ware." These are enormously important sources of information, and, from the point of view of their content, they would seem to qualify in all respects as the type of document libraries have traditionally obtained as a matter of course. For example, libraries have regarded it as normal to provide indices to periodicals as part of their reference holdings. In several instances, now, indices to important journals are available on diskette simply for the cost of the diskette itself. Should the reference room provide the computers and reference diskettes for these journals? Should lending libraries of free ware be maintained? Should users be allowed or even encouraged to copy free ware for use in their offices or at home on their machines?

What of the CD-ROM reference material in this regard? Tools like Grolier's Electronic Encyclopedia will come with software that is intended to enable users to copy material verbatim onto other electronic media for manipulation in word processors or incorporation in its exact form in their own work. If photocopying has posed problems of copyright infringement in the past, it is simply overwhelming to contemplate the potential for abuse in this realm with the widespread diffusion of CD-ROM publication. In a recent conference on CD-ROM technology, sponsored by Microsoft in Seattle, Washington, one participant jested that "autoplagiarize" could be a new command built in to future CD-ROM software, perhaps corresponding to a single keystroke to facilitate the rapid acquisition of information in usable form.

In effect, the university library, by providing the technology for massive "channel switching" of information flow to scholars, could itself become an accomplice in undermining the historic principle of copyright for which it has so long fought so valiantly. The response of publishers to this potential for abuse has often been to price their product so as to include compensation for the effective loss of control over copyright, such that even if the information they provide is copied beyond the bounds of existing copyright regulations, the publisher has still recovered his costs by the inflated price charged for the copyable version of the original. Software firms now regularly advertise "noncopyprotected" versions of their material at higher prices than "copyprotected" materials.

University libraries regularly purchase other sources of information that it would be prohibitive for individuals to buy in order to allow certain kinds of research to proceed. Should they not do so with software? Could they not seek to enter into purchasing or license arrangements with software vendors to enable the enlarged li- 
brary community to have access to numerical or text presentation? In what structural ways does this differ from a serial subscription, for example? Much of what is available in software has been created to meet the needs of a business-user community. This is not surprising: these are the clients who pay, therefore their tunes get played. But what of software that would be specifically useful for academic environments? Should academics and librarians merely wait for it to be provided by commercial companies out of some pro bono obligation? Or should university libraries, in coordination with faculty and university computing facilities, take a more active role in designing, writing, or commissioning useful academic software?

If several universities were to combine their efforts on any one of these levels to generate versatile bibliographic software, libraries would be among the first to benefit, since the ease of user interaction with information sources would be greatly improved. Should libraries take the lead in forging this kind of interuniversity coordination or cooperation? Certainly of all the institutions on campus, the library, through interlibrary indexing systems and loan arrangements, is the one organism that has the longest history of cooperative effort in information sharing. Experience in this realm may be a disadvantage if planning on this level is still confined to "the book," but potentially, librarians should be able to take the initiative in these moves.

Librarians may be the best-positioned community to take necessary collective action in yet another area-the continued acquisition of vital government data. Government agencies, upon the suggestion of the Office of Management and Budget, are seriously considering the possibility of making major sources of government statistics available, at present, only in electronic form. Are the governmentdocument sections of libraries ready to cope with the information in this form? If the production and distribution of this material in electronic form is given over to the private sector in the name of governmental cost-cutting moves, are the universities in a position to be able to pay the new costs for what they used to receive for nominal fees as depository libraries? Are they prepared to reequip the governmentdocuments facilities of their buildings in order to accommodate the necessary workstations, plotters, printers, and trained personnel? Can the universities act effectively together to assure that government agencies will continue to provide information in hard copy? If not, which universities are likely to get left behind in accessing government data? What indirect effects will this have in the long run on the ability of universities to attract certain kinds of faculty and teach certain kinds of subjects to its students? If certain kinds of information parasites do not find nourishing prospects in one environment, they can permanently migrate to new feeding grounds.

\section{Library Cataloging, Preservation, and "Publication" of Its Collections}

The rapidly evolving CD-ROM technology is likely to conflate several previously isolated library functions in the future. For example, with "closed" collections of manuscripts, archival material, private papers, period photo or map collections, etc., it is now becoming feasible for individual institutions to transfer faithful images of this material to CD-ROM storage media in an inexpensive manner. Through what is becoming known as WORM (Write Once, Read Many) equipment, libraries will be able in effect to create their own CD-ROM reference collections. This serves several purposes, simultaneously. First, the material is put on a medium that is very versatile and conveniently accessed by users without endangering the deterioration of the originals. Secondly, the material can be thoroughly cataloged, indexed, and crossreferenced as a simple step in the process, providing powerful access tools for the collections' effective use. Thirdly, to cover the costs of initially undertaking the creation of a master disk of the collections concerned, the library could begin to circulate the CD-ROMs for a fee or simply sell them to other institutions or, indeed, individuals. Entire collections of fixed material including such things as medieval Spanish 
literature, nineteenth-century train schedules, or twentieth-century comic books could be "published" in this manner.

\section{Data/Text Presentation versus Data/Text Manipulation}

When massive amounts of data become available only in machine-readable form, what is the library's responsibility for providing the necessary hardware and software for its presentation and/or analysis? Libraries have traditionally never acquired microfilms without also getting the machinery to make these data sources available for consultation. Will the same be true of data on magnetic tape or disk? In this medium, what is the difference between presentation and analysis? With large amounts of economic statistical data, for example, are printed columns of numbers useful or even meaningful? Is the library obliged to present the information in such a way that the patterns within it can be revealed from the "noise?"

In this instance, then, should statistical packages with graphic display and plotting capability be standard equipment for each library collection handling machinereadable data? What about programs for KWIC (Key Word In Context) sorts on literary texts? Since university computing facilities are regularly equipped with SPSS, SAS, or the like to allow economists, sociologists, psychologists, or statisticians to see patterns in their data, then on what grounds should the library not provide homologous tools for textual manipulation that allow literary critics, students of language, or intellectual historians to perceive previously hidden patterns in their "books"? Should library map collections be expected to provide the enhanced computer graphics hardware and the requisite software to enable researchers to view and analyze LANDSAT tapes upon demand? When museums make large photographic inventories of their collections available for research purposes on laser disk, where should the equipment to "read" these disks be located? in the university museum, in its computer center, or in its research library? When software is provided on CD-ROM disks to manipulate and copy information from the accompanying information bank, what is the library's obligation or liability in providing the hardware to copy, transform, and reformulate this for research and publication by scholars? Embedded in these seemingly mundane equipment issues are fundamental educational decisions that university officials, librarians, and faculty should be invited to reflect upon together.

In addressing these issues there is considerable room for creative symbioses to emerge here between the different lifeforms on campus. Columbia University's announced intentions of integrating many of the library and computer center functions through a mutually accessible computer communications network known as the "Doughnut" may well serve as a national model for this kind of mutualism. Efforts toward cooperative planning could very well be advanced by the Research Libraries Group on an interuniversity basis as well. At the very least, deliberate, toplevel planning should begin at each institution between the administration and those responsible for the libraries and computer facilities as well as representatives from a broad range of faculty disciplines in order to discern the ways different constituencies conceive of the forthcoming evolutionary changes.

\section{CONCLUSION: ORGANISMS, THINGS, AND THE METABOLISM OF THOUGHT}

In developing these planning strategies, it is important to keep in mind that we are dealing not so much with things as we are with life processes. The danger in talking about life-forms as if they were things is that it is all too easy to become dismissive of mere "objects." Consider the book itself, for example. As a "thing,," it can be described as a piece of late medieval technology used as a channel for the extended storage of information markers. As we have seen, there are more efficient, less costly, and more convenient channels for information markers, and I suppose all the information in books could technically be placed on these other channels. Consumers who become accustomed to other kinds of channels may well expect that all 
information they need should be provided to them on these other channels. Where this can only be undertaken at the cost of obtaining or maintaining information in book form, difficult choices will have to be made.

The real tragedy implied in these choices, however, is masked so long as we are dealing with "things," for in the vocabulary of things we think primarily of cost/efficiency ratios, trade-offs, and the like. It is all too easy to obscure the fact that in this manner the interests of some life-forms on campus are going to suffer in terms of their proportional allocation of resources in the system. Depending upon their respective metabolisms, selected life-forms may experience stunted growth, death, and extinction.

This is why we need to be careful, for there are some very delicate life processes sustained by the life-systems currently in place. We ought not dispense with these forms too lightly. The scholars' ultimate concern is with life-the life of the mind. In order to sustain this, they must necessarily form enduring symbioses with information systems that enable them to nourish this delicate form of life. The life of the mind cannot take place in a vacuum, and in many respects what we characterize as creativity or originality involves more accurately a process of reordering previously available thought. It is the act of rearranging that constitutes creativity. Pascal put it with characteristic honesty when he described the activities of his own creative process:

Let no man say that I have said nothing newthe arrangement of the material is new.... Just as the same thoughts differently arranged form a different discourse, so the same words differently arranged form different thoughts. The last thing one does in writing a book is to know what to put first. ${ }^{9}$

In writing a book it is indeed difficult for a scholar to know what to put first. This is necessarily so-not because writers are personally confused, but rather because "the book" is but an artifact, a residue, of yet another process, a life-process that is still only dimly understood, and perhaps never fully describable: the phenomena of thought itself. The writer's task is one of transforming a process (thought) into an object (book). It is an exhausting and exhilarating activity and one that is, unfortunately, all too prone to a kind of arrogance emanating from the illusion of originality. Scholars easily forget that they are locked in coevolution with the life-forms that sustain their thought. In particular, they often neglect the evolution of libraries as a vital aspect of their own survival.

A library's essential task is to arrange the objects to favor the metabolic processes of thought. To feed the life of the mind the scholar devours this ordered information, reformulating it and arranging it again in yet other objects which the library must in turn arrange anew, making them available to nourish the life of yet other minds. Since in all of this the life functions of the scholar and the library are reciprocal, their coevolutionary fates are one.

It is for this reason that mutual discussion is more urgent now than perhaps ever before. I suspect that in this movement toward collective deliberation, librarians will have to take the lead, for there seems to be little awareness-let alone planning-among the faculty at large in the face of the altered information environment we are all beginning to experience. Librarians by virtue of their professional training and daily exposure to these issues are better informed and more likely to see the implications of the coming transformations for the entire educational community.

We started with the sober observation that libraries as we know them may become extinct. The logic of coevolution is such that we as scholars cannot be immune or indifferent to the transformations occurring in library and information science. Indeed we, the members of the scholarly community, must acknowledge that, given the importance of the decisions you as librarians will be making in the coming months and years, our coevolutionary fate is in your hands. Many delicate life-forms depend upon the kinds of environments you choose to sustain or decide to create. Be wise, be kind, be careful. 


\section{REFERENCES AND NOTES}

1. E. Schrodinger, What is Life (New York: Macmillan, 1945), p.72, cited in G. Miller, Living Systems (New York: McGraw-Hill, 1978), p.18.

2. G. Miller, p.13.

3. Ibid., p.12.

4. Online, Inc., "Online '85: Conference and Exposition" conference announcement, Weston, Conn., 1985.

5. Leonard Laub, "The Evolution of Mass Storage," Byte 11, no.5:161-72 (1986).

6. Norman Desmarais, "Laser Libraries," Byte 11, no.5:235-46 (1986).

7. For a review of Grolier's Electronic Encyclopedia, see B. N. Dixon, "The Grolier Electronic Encyclopedia," CD-ROM Review 1, no.1:10-15 (1986).

8. Geoff Simons, The Biology of Computer Live: Survival, Emotion and Free Will (Boston, Birkhauser, 1985), p.18-19.

9. B. Pascal, Pascal's pensées, original ed., 1670, adapted from translation by H. F. Stewart (New York: Pantheon, 1950), p.358.

\section{STATEMENT OF OWNERSHIP AND MANAGEMENT}

College \& Research Libraries is published six times a year by the American Library Association, 50E. Huron St., Chicago, IL 60611. Annual subscription price, \$17.50. American Library Association, owner; Charles R. Martell, editor. Second-class postage paid at Chicago, Illinois. Printed in U.S.A. As a nonprofit organization authorized to mail at special rates (Section 132.122, Postal Service Manual), the purpose, function, and nonprofit status of this organization and the exempt status for federal income tax purposes have not changed during the preceding twelve months.

\section{EXTENT AND NATURE OF CIRCULATION}

" "Average" figures denote the average number of copies printed each issue during the preceding twelve months; "Actual" figures denote actual number of copies of single issue published nearest to filing date-the July 1986 issue.) Total number of copies printed: Average, 13,043; Actual, 13,324. Paid and/or requested circulation: not applicable (i.e., no sales through dealers and carriers, street vendors and counter sales). Mail subscriptions: Average, 11,301; Actual, 11,526. Total paid and/or requested circulation: Average, 11,301; Actual, 11,526. Free distribution by mail, carrier or other means, samples, complimentary, and other free copies: Average, 190; Actual, 222. Total distribution: Average, 11,491; Actual, 11,748. Copies not distributed: office use, left over, unaccounted, spoiled after printing: Average, 1,552; Actual, 1,576. Returns from news agents: not applicable. Total (sum previous three entries): Average, 13,043; Actual, 13,324.

Statement of Ownership, Management and Circulation (PS form 3526, Dec. 1985) for 1986 filed with the United States Post Office Postmaster in Chicago, September 30, 1986. 